\title{
Quality Control Optimization of University Students Training
}

\author{
Elena Yuryevna Levina ${ }^{1}$, Firuza Albertovna Saglam², Anna Ildarovna Skorobogatova ${ }^{2}$, Albert Khanifovich \\ Shaikhlislamov ${ }^{3}$, Viktoriya Ravilyevna Sagitova ${ }^{4} \&$ Albina Raisovna Fayzullina ${ }^{3}$ \\ ${ }^{1}$ The Institute of Pedagogic and Psychology of Professional Education of Russian Academy of Education, Kazan, \\ Russian Federation \\ ${ }^{2}$ Institute of Economics, Management and Law, Kazan, Russian Federation \\ ${ }^{3}$ Kazan Federal University, Kazan, Russian Federation \\ ${ }^{4}$ Kazan Cooperative Institute (Branch) of the Russian University of Cooperation, Kazan, Russian Federation \\ Correspondence: Elena Yuryevna Levina, The Institute of Pedagogic and Psychology of Professional Education \\ of Russian Academy of Education, 420039, Kazan, Isaeva Street, 12, Russian Federation. E-mail: \\ frau.levina2010@yandex.ru
}

Received: September 22, 2014 Accepted: December 17, 2014 Online Published: December 20, 2014

doi:10.5539/ass.v11n2p296 URL: http://dx.doi.org/10.5539/ass.v11n2p296

\begin{abstract}
The purpose of this article is to research the opportunities of university students' training quality control efficiency increase. The presented article contains offers of optimization of students training quality monitoring systems. Industrial plans of goods optional quality control, adapted for system of professional education act as the basis of the presented work. Optimization of the automated testing procedures of knowledge by mathematical modeling and use of methods of consecutive quality control is made in the article. This article is intended for teachers, researchers, heads of the educational institutions dealing with issues of an assessment and improvement of education quality.
\end{abstract}

Keywords: professional education, quality control of students training, the quality control plans, the automated systems of testing, risks assessment

\section{Introduction}

Relevance of a question about improvement of professional education quality, its efficiency and training of competitive experts is widely discussed in pedagogical researches by (Mukhametzyanova, 2005; Ibragimov, 2002; Bermus, 2002; Selezneva, 2002; Potashnik, 2002, etc.), which basis is made by situation that quality of the graduate reflects the quality of a component of educational system or educational process. Thus, it is necessary to take measures toward quality control and its continuous improvement according to the concept introduced in education of "general quality" (Deming, 2011; Dzhuran, 1992; Crosby, 2004; Isikava 1988, Masalimova \& Sabirova, 2014, etc.).

The system basis of an assessment of education quality at the university has to include permanent quality control of the most educational process as deviations of quality parameters found in time allow introducing amendments in technology of training and control that is especially important while developing new subjects or specialties. In a whole, the system of quality assessment of educational process is built on the result of comparison basis of demanded and real indicators of quality as quantitative attributes of compliance measure of quality to the norms established in the higher education, requirements and standards.

Control of assimilation level of students' knowledge that is current, thematic or total control is exercised just in the course of training. The main aim of knowledge and abilities control includes "detection of achievements, students' progress and indication of improvement ways, increasing knowledge and skills in order to create conditions for the subsequent students' inclusion into creative activity" (Bespalko, 1995). Quality of training is considered to be accepted if a student can execute the functions properly, according to the level of requirements imposed by the teacher at this level of studying (Kachalov, 2000).

It is a typical situation now to use the automated systems of testing for quality control of students training for different types of control. Thus it is important to consider the tests themselves (quality and reliability of questions) (Avanesov, 1994), a choice of the test type, the probability of answers guessing (Rudinsky, 2004; Ione \& Limanova, 
2004). Quite often, procedure of an assessment of test results becomes complicated for receiving reliable information (Moiseev et al., 2001) about a real condition of students' knowledge level.

From our point of view, the usage of concept "selective control" of student's knowledge can significantly shorten the period of time for the automated testing and will increase reliability of its results.

\section{Methodological Framework}

The standard of the state acceptance of the industry when the conclusion about quality of products of mass release is made from results of researches of casual selection of big parties, in which the volume and admissible percent of defect is defined in the coordinated documents formulating type and conditions of acceptance is put in the basis of research. Thus it is supposed that in a certain number of cases to allow presence of several percent of defect is cheaper, than to aspire to a complete elimination of low-quality products, raising the price of products by several times.

In accordance with STATE STANDART P 50779.71-99 (GOST P-50779.71-99, 2001) the lot of products is considered qualitative if it includes the percent of the rejected products which isn't exceeding a certain norm set by the consumer. Applying this standard to process of quality control of the educational service provided by higher educational institution to the students, it is possible to tell the following: due to various abilities of the students of one group, quite often there is a percent of students badly mastered this or that subject (defect). However having checked the majority of students who have passed control procedures, it is possible to draw conclusions about quality of technology of training as it is cheaper to allow presence of small number of slip behind students in the group, than to aspire to a complete elimination of defect in the course of training, entering correcting courses and increasing training cost. For all that, if the number of slip behind students considerably (the percent of defect is higher than admissible)-that it is necessary to change technology of teaching or control. Similarly it turns out in a case with one student when he is asked to tell a great deal of material. Absolute level of knowledge is seldom reached because of different circumstances; therefore some mistakes may be done by the students for satisfactory passing an examination or a set-off. But if there are a lot of mistakes in the student's answer, the exam (set-off) is not accepted. But the psychological and pedagogical factors that influence the quality of training and results of testing are diverse and are little predicted that makes using of special methods of mathematical processing of control results inevitable.

\section{Results}

The quality control of goods ordered by the standard includes some plans of selective control: the one-stage, two-stage, multistage sequential plan. Thus the main characteristic of a lot of products is a general share of defective products $\mathrm{Q}=\mathrm{D} / \mathrm{N}$, where $\mathrm{N}$-the volume of the party, and $\mathrm{D}$-number of defect in the whole party. Practically the general share of Q (or number $\mathrm{D}$ ) is unknown and is estimated by results of casual control selection by the volume of $n$ products from the same party. Share of defective products in selection: $q=d / n$, where $d$ is quantity of defective products in $\mathrm{n}$ selection.

Thus, the solution of the task includes reliable determination of the unknown quantity D proceeding from known quantity of products in party $\mathrm{N}$, numbers of products in $\mathrm{n}$ selection and number of defective products in $\mathrm{d}$ selection.

The plan of statistical control is understood as a system of rules establishing methods of a casual choice for checking products from the party, and also conditions for $\mathrm{N}, \mathrm{n}, \mathrm{d}$ so that the party control should be accepted, rejected or continued (to increase value $\mathrm{n}$ ).

Minimization of casual selection volume $\mathrm{n}$ means reduction of labor input and reduction of economic expenses for process of computer knowledge control, or when checking residual knowledge of students group in a certain subject or when checking one student asking him a large number of test questions.

We offer adaptation of the consecutive plan of control to a system of automated testing at the university. During the adaptation period the amount $\mathrm{n}$ of fraction selection isn't established in advance and the approximate assessment of quality is considered known already at small values $\mathrm{n}$; each new question (test) assessment is specified. The decision to stop testing is made because of teacher's maximum risks (probabilities of overestimated grade) and student's risks (probability of underestimated grade).

Thus, during sequential control the number of the asked questions $\mathrm{n}$ is calculated according to statistical criteria of reliability. So this $\mathrm{n}$ is turned out to be a random volume, unequal for various students. However the result of control receives statistical justification. The problem of a right choice of control plan includes minimizing of the teacher's risk to give above deserved grade and student's risk to get a grade lower than his or her real level of knowledge. 
We will illustrate operation of the automated module using the plan of knowledge control with the following example. Suppose, it is necessary to estimate the student's knowledge of 150 questions on a subject. The criteria of estimation are presented in the table.

Criteria of giving grades according to the results of testing are shown in Table 1 (see Table 1).

Table 1. Criteria of giving grades according to the results of testing

\begin{tabular}{ll}
\hline Grade & Shares $\mathrm{z}$ of correct answers \\
\hline Excellent & $\mathrm{z} \geq 0,89$ \\
Good & $0,89>\mathrm{z} \geq 0,62$ \\
Satisfactory & $0,62>\mathrm{z} \geq 0,34$ \\
Poor & $0,34>\mathrm{z} \geq 0,01$ \\
\hline
\end{tabular}

The students are asked questions; one at a time in the course of knowledge control, the quantity of the correct answers is counted at each step. Operational characteristics of control are also calculated the teacher's and student's risks by interpolating for each assessment using the borders of intervals from the table. For example, if $\mathrm{n}$ $=10$ questions are asked from all 150 questions by the present moment and only 7 questions have the right answers, the result of examination can be assumed in any case, i.e. it is still possible to assume any total assessment. Thus the assessment "good" seems the most probable since the share of the correct answers makes 0.7.

On the other hand, if "good" is taken as an entity, it is possible to estimate probabilities that the real total assessment after all will be higher in the course of testing, (student's risk) or below (teacher's risk). So the student's risk is defined as probability of that the student as a result of selective $(\mathrm{M}<150)$ control will get the underestimated grade, and risk of acceptance-as probability of that the grade will be higher than the real one that corresponds the results of examination of all 150 questions. As a result of calculation for present $\mathrm{Q}$ example $=150$ and a stage $\mathrm{n}=$ $10, z=0.7$ is got. The mentioned risks of mistakes make respectively a volume about 0.1 and 0.2 for grade "good". Thus the risk of the student and acceptance are respectively close to zero and one for the grade "excellent", and on the contrary, unit and zero for the grade "poor".

The explicate procedure of knowledge quality control of a student is presented in Figure 1.

It is clear from Figure 1 that minimum risks take place while determining grade "good" at a stage $n=10$, however a grade "satisfactory" remains rather probable. This opportunity is more and more realized gradually if continue testing: the risk of acceptance becomes rather big $(70 \%)$ when $n=20$. When $n=30$ it is approximately the same for "satisfactory" that for "good" at $\mathrm{n}=10$, and when $\mathrm{n}=50$ "good" it is already possible to estimate knowledge definitely enough, i.e. with risks of a mistake both toward big and or small side-about $1 \%$.

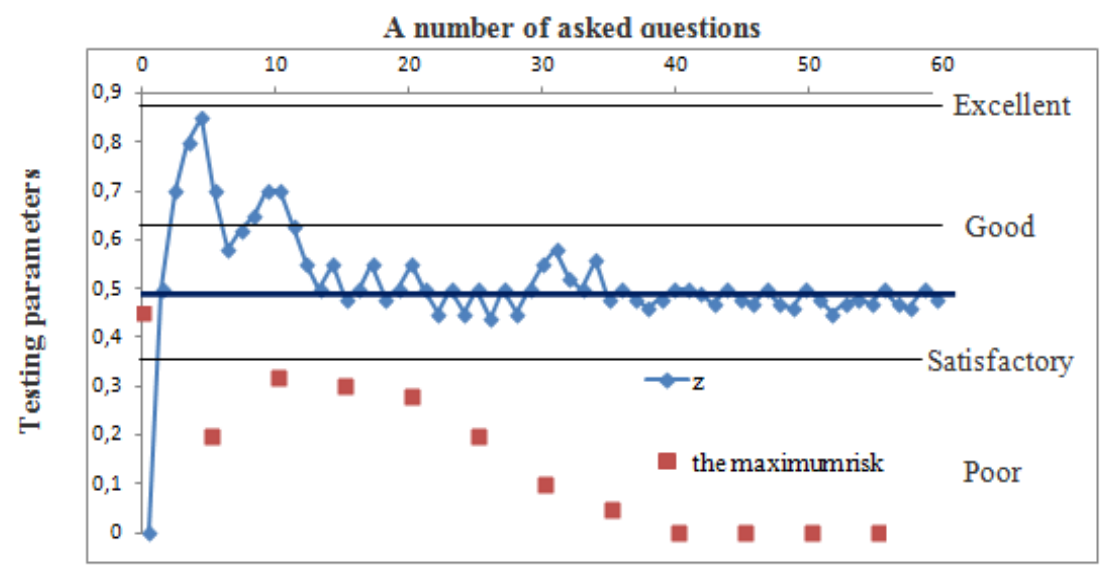

Figure 1. Dependences of the current value of the registered knowledge level of $\mathrm{z}=\mathrm{v} / \mathrm{n}$ and risk defined as a maximum among student and teacher's risks from $n$ at a testing stage till $n=60$

As a result of the testing held till the end $(n=150)$, value $z=0.500$ is received, it is really close to value $z=0.527$ of stage $n=50$. By the way values $z=0.55$ are received at $n=20$, close to a total share of the right answers 0.527 . 
However it made no sense to trust this value, because of big risks to overestimate or underestimate the grade. It is visible that during control the current value $\mathrm{z}$ appeared in the frame of the table, defined for the grade "satisfactory", already at $\mathrm{n}=12$ and at further testing (at $\mathrm{n}>12$ ) it didn't leave the frame any more. Thus probabilities of really different assessment were less than $10 \%$ at $n=30$ when the student was asked about one fourth part of the questions (i.e. at $\mathrm{n}>35$ ).

It is possible to stop the testing earlier under more favorable circumstances at the level of risks about $1 \%$ when a share of the asked questions is less than one fifth.

Practice of application (more than 5000 tests were carried out) of the developed program module in educational process showed that in $24 \leq \mathrm{Q} \leq 150$ more than in $75 \%$ of cases it is possible to reduce checking procedure of auditory material retention twice and more, thus the risks of getting inexact grade of training quality essentially decrease.

\section{Discussions}

The basis of research involved the works of domestic and foreign authors concerning questions of quality management, an assessment of training quality, methods of diagnostics of students training quality, development of automated testing systems.

Referring to the concept of "general quality" (Deming, 2011; Dzhuran, 1992; Crosby, 2004; K.Isikava, 1988, etc.), the quality standards (ISO 9000) as the educational service provided by higher educational institution, the development of provisions of methodological base of a quality control system of education was initiated by (Muhametzyanova, 2005; Ibragimov, 2002; Bermus, 2002; Selezneva, 2002; Potashnik, 2002, etc.). Features of application of mathematical statistics methods in pedagogical researches and ways of pedagogical measurements and test diagnostics were considered in works of (Bespalko, 1995; Avanesov, 1994; Kachalov, 2000, Bakar \& Hanafi, 2007, etc.).

Modern researches in the field of mathematical modeling of knowledge testing and identification of real level of students' proficiency are presented in (Moiseyev, Pyatirublevy, \& Tarantseva's, 2001; researches; Jone \& Limanova, 2004; Rudinsky, 2004, etc.).

However, the question of adaptation of plans of selective quality control of products toward problems of students' quality training assessment at the university wasn't considered in the real researches.

\section{Conclusion}

Thus, the optimization of quality assessment procedures of students' knowledge was made on the basis of adaptation of theoretical bases of quality control plans of industrial products toward conditions of the automated testing of students at higher educational institution. Possibility of methods use of consecutive quality control of group of the objects approved at the state standards and used in the industry is shown. Use of the consecutive plan of selective control with an assessment of risk of the teacher (to give the overestimated grade) and risk of students (to get the underestimated grade) in the system of test control is carried out for the first time. Imitating modeling of plans of selective control is carried out, the software of procedure of testing with estimates of risks of the teacher and the student which practice of application showed considerable reduction of time for procedure of testing and high precision of estimation is developed.

\section{References}

Avanesov, V. S. (1994). Scientific problems test knowledge control. Moscow Research Center of the quality of training, 135.

Bakar, A. R., \& Hanafi, I. (2007). Assessing employability skills of technical-vocational students in Malaysia. $J$. Soc. Sci., 3, 202-207.

Bermus, A. G. (2002). Quality management professional pedagogical education (p. 288). Rostov-on-Don Herzen University Publisher.

Bespalko, V. P. (1995). Pedagogy and advanced technology training (p. 336). Moscow Institute Professor. arr. RAO.

Crosby, F. (2004). Quality and I. Life business in America. Moscow Standards and Quality publishing, 264.

Deming, E. (2011). Out of the crisis: A new paradigm of people management systems and processes (p. 419). Moscow Alpina Publisher.

GOST P-50779.71-99 Statistical methods. (2001). The main provision Russian State Standard (p. 183). Moscow-Publishing IPC Standards. 
Ibragimov, G. I. (2002). State educational standard and system control the quality of graduates. $J$. Vocational Educ., 1, 10-14.

Ione, S. D., \& Limanova, N. I. (2004). Increased monitoring of students' knowledge in computer systems testing (pp. 22-24). Actual problems of university and technical education in Russia: Sb. Conf. Interregional Scientific Conference. Samara, SSTU.

Ishikawa, K. (1988). Japanese quality management. Moscow Economics publishing, 214.

Juran, J. M. (1992). Strategic Quality Management (p. 346). NY McGra-Hill Inc.

Kachalov, V. I. (2000). Problems of quality management in higher education. Notes Quality Manager. $J$. Standards and Quality, 5-7, 9-12.

Masalimova, A. R., \& Sabirova, L. L. (2014). Multi-dimensional classification of types and forms of corporate education. American Journal of Applied Sciences, 11, 1054-1058. http://dx.doi.org/10.3844/ajassp.2014. 1054.1058

Moiseev, V. B., Pyatyrublevyi, L. G., \& Tarantseva, K. R. (2001). Statistical approach to decision-making on the test results for tests of the open form. J. Open Education, 1, 51-57.

Muhametzyanova, G. V. (2005). Professional Education: Problems of Quality and Scientific Methodical Support (1st ed., p. 319). Kazan Magarif.

Potashnik, M. M. (2002). Quality of Education: Problems and Management Technologies: Questions and Answers (1st ed., p. 352). Moscow Pedagogical Society of Russia.

Rudinskiy, I. D. (2004). Basics Formal-Structural Simulation Training Systems and Automation Testing of Pedagogical Knowledge (1st ed., p. 204). Moscow Hotline-Telecom Publisher.

Selezneva, N. A. (2002). Quality of Higher Education as an Object of Systematic Research (1st ed., p. 95). Moscow Research Center of the Quality of Training.

\section{Copyrights}

Copyright for this article is retained by the author(s), with first publication rights granted to the journal.

This is an open-access article distributed under the terms and conditions of the Creative Commons Attribution license (http://creativecommons.org/licenses/by/3.0/). 